\title{
Replicação e excreção viral durante a infecção aguda e após a reativação da latência induzida por dexametasona em bezerros inoculados com os herpesvírus bovinos tipo 1 (BHV-1) e 5 (BHV-5) ${ }^{1}$
}

\author{
Viral replication and shedding during acute infection and after dexamethasone induced reativation of latency \\ in calves inoculated with bovine herpesvirus type 1 (BHV-1) and 5 (BHV-5)
}

\begin{abstract}
Fernanda Silveira Flores Vogel ${ }^{2}$ Marcelo de Lima ${ }^{3}$ Eduardo Furtado Flores $^{4}$ Rudi Weiblen ${ }^{5}$ Evandro Reinoldo Winkelmann ${ }^{6}$ Sandra Vanderli Mayer ${ }^{3}$ Ketty Cristina Mazzutti ${ }^{6}$ Sandra Arenhart $^{6}$
\end{abstract}

\section{- NOTA -}

RESUMO

Nesse estudo, comparou-se a eficiência de estabelecimento e reativação da infecção latente pelos herpesvírus bovinos tipos 1 e 5 ( $B H V-1$ e 5) em bezerros. Bezerros inoculados pela via intranasal com uma amostra de BHV-1 (SV-265, n=6) ou BHV-5 (SV-507, n=6) apresentaram corrimento nasal discreto a moderado e excretaram vírus em secreções nasais em títulos de até $10^{7,81} \mathrm{DICC}$. $/ \mathrm{ml}$ (dose infectante para $50 \%$ dos cultivos celulares) durante um período médio de 10,5 dias (6-15 [BHV-1]) ou títulos de até 10,7 DICC $_{50}$ $m l$ durante 15,3 dias (13-18 [BHV-5]). A administração de dexametasona (Dx;0,5mg/kg, via endovenosa) aos 60 dias pós-inoculação (pi) resultou em reativação da infecção em todos os animais inoculados. $O$ vírus foi detectado em secreções nasais dos bezerros inoculados com o BHV-1 em títulos de até $10^{5,5} \mathrm{DICC}_{50} / \mathrm{ml}$ por 6 a 9 dias $(\bar{x}: 7,8)$ e em títulos de até $10^{6,1} \mathrm{DICC}_{50} / \mathrm{ml}$ (durante 3 a 12 dias, $\bar{x}: 7,5$ dias) nos bezerros inoculados com o BHV-5. Os resultados obtidos demonstraram que tanto o BHV-1 quanto o BHV-5 foram capazes de estabelecer e reativar a infecção latente em níveis semelhantes.

Palavras-chave: herpesvírus bovino tipo 1, BHV-1, BHV-5, dexametasona, infecção latente.

\begin{abstract}
The efficiency of the establishment and reactivation of latent infection by bovine herpesviruses types 1 and 5 (BHV-1 and 5) was compared. Calves inoculated intranasally with BHV-1 (SV-265, n=6) or BHV-5 (SV-507, $n=6)$ presented a mild to moderate nasal discharge and shed virus in nasal secretions in titers up to $10^{7.81} \mathrm{TCID} 50 / \mathrm{ml}$ (mean tissue culture infectious dose) during an average of 10.5 days (6-15 [BHV-1]) or up to $10^{6.7} \mathrm{TCID}_{50} / \mathrm{ml}$ during 15.3 days (13-18 [BHV-5]). Dexamethasone administration (Dx; $0.5 \mathrm{mg} / \mathrm{kg}$ ) at day $60 \mathrm{pi}$ resulted in reactivation of the infection in all calves. Virus shedding in nasal secretions was detected in titers up to $10^{5.5}$ TCID ${ }_{50} / \mathrm{ml}$ during 6 to 9 days (mean: 7.8) in calves inoculated with BHV-1 and in titers up to $10^{6.1} \mathrm{TCID} \mathrm{D}_{5} \mathrm{ml}$ ( 3 to 12 days, mean: 7.5) in calves inoculated with BHV-5. These results showed that BHV-1 and BHV-5 were capable of establishing and reactivating the latent infection at comparable levels.
\end{abstract}

Key words: bovine herpesvirus type 1, BHV-1, BHV-5, dexamethasone, latent infection.

\footnotetext{
${ }^{1}$ Trabalho realizado com suporte financeiro do Conselho Nacional de Desenvolvimento Científico e Tecnológico (CNPq), Coordenação de Aperfeiçoamento de Pessoal de Nível Superior (CAPES) e Financiadora de projetos (FINEP), (Pronex em Virologia Veterinária, 215/96).

${ }^{2}$ Médico Veterinário, MSc, Doutor.

${ }^{3}$ Mestrando em Medicina Veterinária, Universidade Federal de Santa Maria (UFSM).

${ }^{4}$ Médico Veterinário, MSc, Doutor, Departamento de Medicina Veterinária Preventiva, Centro de Ciências Rurais, e Departamento de Microbiologia e Parasitologia, UFSM, 97105-900 Santa Maria, RS. Bolsista do CNPq (520758/96-0). Fone/fax: 55-220-8034. E-mail: flores@ccr.ufsm.br. Autor para correspondência.

${ }^{5}$ Médico Veterinário, MSc, Doutor, Departamento de Medicina Veterinária Preventiva, Centro de Ciências Rurais, e Departamento de Microbiologia e Parasitologia, UFSM. Bolsista do CNPq(520161/97-1).

${ }^{6}$ Estudante do curso de Medicina Veterinária, UFSM. Bolsista de Iniciação Científica, CNPq.
} 
Os herpesvírus bovinos tipos 1 (BHV-1) e 5 (BHV-5) são vírus DNA, envelopados, membros da família Herpesviridae, subfamília Alphaherpesvirinae (ROIZMAN, 1992). O BHV-1 apresenta distribuição mundial e a infecção de bovinos soronegativos pode resultar em doença respiratória, genital ou abortos (KAHRS, 2001). O BHV-5, previamente classificado como um subtipo do BHV-1, tem sido associado a surtos esporádicos de meningoencefalite em vários países, inclusive no Brasil (STUDDERT, 1989; WEIBLEN et al., 1989). O BHV-1 e o BHV-5 são muito semelhantes nos aspectos morfológicos, antigênicos e moleculares, mas diferem no potencial neuropatogênico (METZLER et al., 1986). O BHV-1 geralmente não replica no sistema nervoso central (SNC), enquanto o BHV-5 invade e replica no SNC produzindo doença neurológica severa (STUDDERT, 1989; MEYER et al., 2001).

Já foi demonstrado que tanto o BHV-1 quanto o BHV-5 estabelecem infecção latente nos seus hospedeiros após a infecção aguda (ROCK, 1994; ASHBAUGH et al., 1997; PEREZ et al., 2002). No entanto, diferenças importantes na região do gene relacionado à latência LAT/LTR entre o BHV-1 e BHV5 sugerem que esses vírus possam diferir na capacidade de estabelecer e reativar a infecção latente (DELHON et al., 2003). O presente estudo teve como objetivo comparar a eficiência de estabelecimento e reativação da infecção latente pelo BHV-1 e BHV-5 em bezerros.

Seis bezerros soronegativos foram inoculados pela via intranasal com a amostra SV-265 de BHV-1 (FRANCO et al., 2002; dose de $10^{6} \mathrm{DICC}_{50}$ - doses infectantes para $50 \%$ dos cultivos) e seis com a amostra SV-507 de BHV-5 (DELHON et al., 2003; dose de $10^{6} \mathrm{DICC}_{50}$ ). Os dois grupos foram mantidos a campo, em potreiros distantes para evitar infecção cruzada. Nos dias seguintes à inoculação, secreções nasais coletadas foram submetidas à pesquisa e quantificação de vírus. Sessenta dias após a inoculação (pi), todos os animais foram submetidos à administração de Dexametasona (Dx; dose única de $0,5 \mathrm{mg} / \mathrm{kg}$; via intravenosa); e nos dias seguintes (pós-dexametasona, pDx) as secreções nasais foram submetidas à pesquisa e quantificação de vírus. Células MDBK foram utilizadas para isolamento de vírus e testes de soro-neutralização (SN).Todos os procedimentos de coleta de material e pesquisa de vírus em secreções nasais foram executados por duas equipes independentes de técnicos, para evitar contaminação entre os grupos e amostras. Mesmo assim, a identidade dos vírus isolados foi confirmada por imunofluorescência indireta (IFI) das células inoculadas, utilizando-se um anticorpo monoclonal que é capaz de diferenciar BHV-5 de BHV-1 (OLDONI et al., 2004). Amostras de soro coletadas após a infecção aguda (30dpi) e após a reativação foram submetidas à pesquisa de anticorpos neutralizantes contra o BHV-1 e BHV-5 pela técnica de SN.

Os animais inoculados com o BHV-1 excretaram vírus nas secreções nasais do dia 1 ao dia 15 pi e os animais inoculados com o BHV-5 excretaram vírus do dia 1 ao dia 18 pi (Tabela 1). O pico de excreção viral para os dois vírus ocorreu entre os dias 3 e 5 pi (títulos máximos de $10^{7,8} \mathrm{DICC}_{50} / \mathrm{ml}$ para o BHV-1; e de $10^{6,7} \mathrm{DICC}_{50} / \mathrm{ml}$ no grupo do BHV-5). Os animais inoculados apresentaram apenas corrimento nasal discreto, passando de mucoso a mucopurulento entre os dias 4 e 9 pi. Todos os animais inoculados soroconverteram para os respectivos vírus após a infecção aguda, com títulos de anticorpos neutralizantes que variaram de 8 a 128 no dia 30 pi (Tabela 1).

A administração de Dx no dia 60 pi resultou em reativação viral em todos os animais inoculados, iniciando entre os dias 4 e 6 pDx (BHV-1); e entre os dias 1 e 8 pDx (BHV-5). O pico de excreção viral foi detectado entre os dias 7 e $10 \mathrm{pDx}$. O maior título viral excretado foi de $10^{5,5} \mathrm{DICC}_{50} / \mathrm{ml}$ para o BHV-1; e de $10^{6,1} \mathrm{DICC}_{50} / \mathrm{ml}$ (BHV-5). Nenhuma alteração clínica foi observada após a administração de Dx. A soroconversão ao BHV-1, tanto após a infecção aguda quanto após a reativação, foi de magnitude maior do que para o BHV-5. O significado dessas observações merece investigação.

Os resultados demonstraram que tanto o BHV-1 quanto o BHV-5 foram capazes de estabelecer e reativar a infecção latente em níveis semelhantes. Embora durante a infecção aguda o BHV-5 tenha sido excretado durante um período maior (15,1 dias contra 10,5 dias do BHV-1), após a reativação os dois vírus foram excretados com duração semelhante (BHV-1: 7,8 dias; BHV-5: 7,5 dias) e em títulos semelhantes. Portanto, considerando-se a excreção viral mensurável por meio de isolamento e quantificação de vírus, podese concluir que o BHV-1 (SV-265) e o BHV-5 (SV-507) foram capazes de estabelecer e reativar infecções latentes em níveis semelhantes em bezerros inoculados. Esses resultados sugerem que as diferenças observadas entre estes vírus no gene associado à latência (LAT/LTR; DELHON et al., 2003) parecem não se refletir em capacidade distinta em estabelecer e reativar a infecção latente. Não se pode desconsiderar, no entanto, que podem existir diferenças entre amostras de campo de BHV-1 e BHV-5 e também diferenças de expressão do LAT/LTR ou ainda genes equivalentes entre esses vírus. 
Tabela 1 - Excreção viral em secreções nasais durante a infecção aguda e após a administração de dexametasona (Dx) em bezerros inoculados com os herpesvírus bovinos tipos 1 (BHV-1) e 5 (BHV-5).

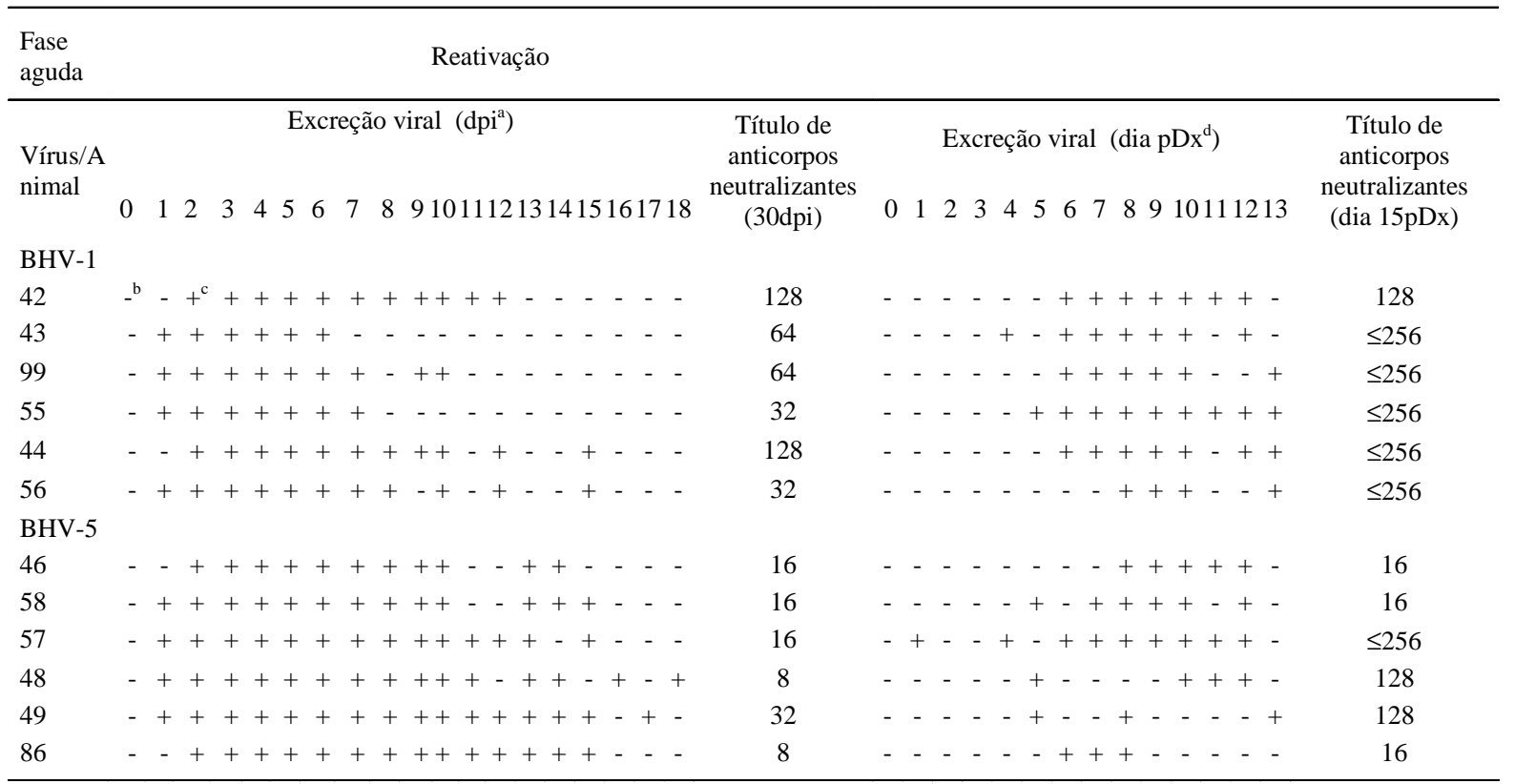

a - Dia após a inoculação; ${ }^{\text {b }}$ - Negativo para vírus; ${ }^{\text {c }}$ - Positivo para vírus; ${ }^{\text {d }}$ - Dia após a administração de Dx

\section{REFERÊNCIAS BIBLIOGRÁFICAS}

ASHBAUGH, S.E. et al. Specific detection of shedding and latency of bovine herpesvirus 1 and 5 using a nested polymerase chain reaction. Journal of Veterinary Diagnostic Investigation. v.9, p.387-394, 1997.

DELHON, G. et al. Genome of Bovine herpesvirus 5. Journal of Virology, v.77, n.19, p.10339-10347, 2003.

FRANCO, A.C. et al. A Brazilian glycoprotein E-negative bovine herpesvirus type $1.2 \mathrm{a}(\mathrm{BHV}-1.2 \mathrm{a})$ mutant is attenuated for cattle and induces protection against wild-type virus challenge. Pesquisa Veterinária Brasileira, v.22, p.135140,2002 .

KAHRS, R.F. Infectious bovine rhinotracheitis and infectious pustular vulvovaginitis. In: Viral diseases of cattle. 2ed. Ames, Iowa : Iowa State University, 2001. p.159-170.

METZLER, A.E. et al. Bovine herpesvirus type 1: molecular and antigenic characteristics of variant viruses isolated from calves with neurological disease. Archives of Virology, v.87, p.205-217, 1986.
MEYER, G. et al. Comparative pathogenesis of acute and latent infections of calves with bovine herpesvirus types 1 and 5. Archives of Virology, v.146, p.633-652, 2001.

OLDONI, I. et al. Production and characterization of monoclonal antibodies to a Brazilian bovine herpesvirus type 5 (BHV-5). Brazilian Journal of Medical and Biological Research, v.37, n.2, p.213-221, 2004.

PEREZ, S. et al. Primary infection, latency and reactivation of bovine herpesvirus type 5 in the bovine nervous system. Veterinary Pathology, v.39, p.437-444, 2002.

ROCK, D.L. Latent infection with bovine herpesvirus type1. Seminars in Virology, v.5, p.233-240, 1994.

ROIZMAN, B. The family Herpesviridae: an update. Archives of Virology, v.123, n.3-4, p.432-445, 1992.

STUDDERT, M.J. Bovine encephalitis herpesvirus. Veterinary Record, v.125, p.584, 1989.

WEIBLEN, R. et al. Bovine meningo-encephalitis from IBR virus. Veterinary Record, v.124, p.666-667, 1989. 